\title{
The Effect of Antiviral Therapy on Serum Cholesterol Levels in Chronic Hepatitis C
}

\author{
Eun Sun Jang, Ji-Eon Won, Jae II Jung, Sang-Hyub Lee, Jin Wook Kim, and Sook-Hyang Jeong \\ Department of Internal Medicine, Seoul National University Bundang Hospital, Seoul National University College of Medicine, Seongnam, \\ Korea
}

Background/Aims: The aims of this study were to evaluate the effect of antiviral therapy on serum total cholesterol (TC) levels and to investigate the factors related to serum TC changes in chronic hepatitis $\mathrm{C}(\mathrm{CHC})$ patients. Methods: A total of $94 \mathrm{CHC}$ patients, the majority of whom were infected with genotype 1 or 2 and were receiving antiviral therapy, were consecutively enrolled. TC levels before treatment, at week 4, at the end of treatment (EOT), and at 24 weeks after the EOT were analyzed, along with factors related to pre- and post-treatment TC levels. Results: Pretreatment TC levels in the sustained virologic response (SVR) group $(167 \pm 3.6 \mathrm{mg} /$ $\mathrm{dL})$ and the non-SVR group $(158 \pm 8.3 \mathrm{mg} / \mathrm{dL})$ were similar, and both decreased during antiviral therapy. The TC levels at 24 weeks after the EOT significantly increased in the SVR group $(183 \pm 4.7 \mathrm{mg} / \mathrm{dL})$, but not in the non-SVR group $(160 \pm 7.1 \mathrm{mg} / \mathrm{dL}, \mathrm{p}=0.044)$ after adjusting for the pretreatment TC levels. The grade of hepatic fibrosis, as measured by the METAVIR score or the aspartate aminotransferaseplatelet ratio index (APRI), but not viral load $(p=0.119)$, was an independent variable associated with the pretreatment TC levels (METAVIR score, $p=0.011$; APRI, $p=0.033$ ). After adjusting for the presence of a SVR by longitudinal data analysis using generalized estimating equations, the independent variable APRI was associated with the serum TC level after antiviral therapy $(p=0.014)$, whereas a SVR was associated with the serum TC level only with marginal statistical significance ( $p=0.084)$. Conclusions: Serum TC levels increased in the SVR group after antiviral therapy for $\mathrm{CHC}$; however, this was probably due to an improvement in liver fibrosis rather than the eradication of virus. (Gut Liver 2011;5:356-362)

Key Words: Chronic hepatitis C; Therapeutics; Cholesterol; Fibrosis; Sustained virologic response

\section{INTRODUCTION}

Because the liver plays a fundamental role in lipid metabolism, serum total cholesterol (TC) level decreases among patients with chronic liver disease as severity of liver disease increases. ${ }^{1,2}$ Chronic hepatitis C virus (HCV) infection induces more remarkable decrease of TC and lipoprotein levels when compared to other types of liver disease, even in the early stage of HCV infection, prior to development of liver cirrhosis. ${ }^{3-6}$ Many investigators have documented the direct effects of HCV on lipid metabolism. ${ }^{6-9}$ Among patients infected with genotype 3, low TC level correlated with high HCV ribonucleic acid (RNA) level and a high degree of hepatic steatosis. ${ }^{10}$ Moreover, hypocholesterolemia was reversed after antiviral therapy in sustained virologic responders infected with genotype $3 \mathrm{HCV},{ }^{11}$ and high TC levels prior to antiviral therapy may indicate good treatment outcomes. $^{12}$

However, a study of the effect of HCV infection or of antiviral therapy on cholesterol metabolism has been limited in areas where genotype 1 or 2 is prevalent, such as in the Asia-Pacific area. ${ }^{13-15}$ In addition, clinical factors correlated with pretreatment serum TC levels in chronic hepatitis C (CHC) and predictors of change of TC levels after antiviral therapy have not been clearly elucidated, particularly in non-3 genotype infection.

The aims of this study were to evaluate the effect of antiviral therapy on serum TC level according to antiviral response, and to investigate factors related to pretreatment and post-treatment TC levels in CHC patients.

\section{MATERIALS AND METHODS}

\section{Patients}

A total of 94 CHC patients treated with interferon (IFN)- $\alpha$,

Correspondence to: Sook-Hyang Jeong

Department of Internal Medicine, Seoul National University Bundang Hospital, Seoul National University College of Medicine, 300 Gumi-dong, Bundang-gu, Seongnam 463-707, Korea

Tel: +82-31-787-7017, Fax: +82-31-787-7052, E-mail: jsh@snubh.org

Received on December 16, 2009. Accepted on January 10, 2011.

pISSN 1976-2283 eISSN 2005-1212 http://dx.doi.org/10.5009/gnl.2011.5.3.356

(a) This is an Open Access article distributed under the terms of the Creative Commons Attribution Non-Commercial License (http://creativecommons.org/licenses/by-nc/3.0) which permits unrestricted non-commercial use, distribution, and reproduction in any medium, provided the original work is properly cited. 
pegylated IFN $\alpha-2 a$, or $\alpha-2 b$ combined with ribavirin and completely evaluated for virologic response were consecutively enrolled at Seoul National University Bundang Hospital between October 2003 and October 2008. CHC was defined by detectable serum anti-HCV antibodies, as well as HCV RNA for more than 6 months. Exclusion criteria included chronic liver disease caused by other than HCV (i.e., hepatitis B viral hepatitis, nonalcoholic steatohepatitis, alcoholic liver disease, autoimmune hepatitis, primary biliary cirrhosis, sclerosing cholangitis, Wilson's disease), human immunodeficiency virus infection, or hepatocellular carcinoma.

\section{Methods}

Retrospective review of electronic medical records and meticulous data collection were performed. The study protocol was approved by the Institutional Review Board of Seoul National University Bundang Hospital.
Presence of liver cirrhosis was evaluated by ultrasonography, computed tomography, and/or liver biopsy. Among the total of 94 patients, 60 cases underwent liver biopsy; slides were reviewed by an experienced liver pathologist who was blinded to the clinical course, according to the METAVIR scoring system. ${ }^{16}$ As a simple and validated serum marker of hepatic fibrosis, aspartate aminotransferase (AST)-platelet ratio indexes (APRI) [AST $(/ \mathrm{ULN}) \times 100 /$ platelet $\left.\left(\times 10^{9} / \mathrm{L}\right)\right]$ were calculated. ${ }^{17-20}$

Treatment responses were defined as early virologic response (EVR), a decrease of more than $2 \log _{10}$ serum HCV RNA at week 12 of treatment, and end-of-treatment response (ETR), undetectable serum HCV RNA at week 24 (for genotype 2 or 3) or at week 48 (for genotype 1 or 4 ) of antiviral therapy. Sustained virologic response (SVR) was defined as continued undetectable HCV RNA at 24 weeks after end-of treatment (EOT). Serum TC, alanine aminotransferase, albumin, and APRI were recorded at pretreatment, week 4 of treatment, EOT, and 24 weeks after

Table 1. Comparison of the Clinical Characteristics of the Sustained Viral Response (SVR) Group and the Non-SVR Group after Antiviral Therapy for Chronic Hepatitis C

\begin{tabular}{|c|c|c|c|c|}
\hline Characteristic & Overall $(\mathrm{n}=94)$ & SVR (+) $(n=72)$ & SVR (-) (n=22) & $\mathrm{p}$-value \\
\hline Age, yr & $53.4 \pm 11.2$ & $52.6 \pm 11.3$ & $55.9 \pm 10.9$ & 0.226 \\
\hline Male, n (\%) & $52(55.3)$ & $45(62.5)$ & $7(31.8)$ & 0.011 \\
\hline BMI, kg/m² & $24.0 \pm 2.7$ & $23.9 \pm 2.7$ & $24.1 \pm 2.6$ & 0.866 \\
\hline Liver cirrhosis, $\mathrm{n}(\%)$ & $23(24.5)$ & $13(18.1)$ & $10(45.5)$ & 0.009 \\
\hline \multicolumn{5}{|l|}{ Pathology } \\
\hline Fibrosis, Grade 3/4, n/N (\%) & $15 / 60(25.0)$ & $11 / 45(24.4)$ & $4 / 15(26.7)$ & 1.000 \\
\hline \multicolumn{5}{|l|}{ Laboratory findings } \\
\hline Platelet, $\times 10^{3} / \mu \mathrm{L}$ & $173.0 \pm 81.0$ & $181.6 \pm 83.8$ & $144.7 \pm 64.8$ & 0.062 \\
\hline Total cholesterol, mg/dL & $164.8 \pm 32.9$ & $166.8 \pm 30.9$ & $158.3 \pm 39.0$ & 0.290 \\
\hline Albumin, g/dL & $4.1 \pm 0.3$ & $4.1 \pm 0.3$ & $4.0 \pm 0.4$ & 0.086 \\
\hline ALT, IU/L & $112.2 \pm 93.9$ & $118.3 \pm 100.3$ & $92.2 \pm 67.0$ & 0.257 \\
\hline Prothrombin time, INR & $1.07 \pm 0.12$ & $1.06 \pm 0.11$ & $1.12 \pm 0.13$ & 0.050 \\
\hline Genotype 1, n (\%) & 38 (40.4) & $26(36.1)$ & $12(54.5)$ & 0.123 \\
\hline HCV RNA, log IU/mL & $5.5 \pm 0.8$ & $5.4 \pm 0.8$ & $5.9 \pm 0.5$ & 0.049 \\
\hline APRI & $1.4 \pm 1.1$ & $1.4 \pm 1.2$ & $1.5 \pm 1.1$ & 0.719 \\
\hline \multicolumn{5}{|l|}{ Treatment } \\
\hline Type & & & & 0.782 \\
\hline PegIFN $\alpha-2 a, n(\%)$ & 25 (26.6) & $20(27.8)$ & $5(22.7)$ & \\
\hline PegIFN $\alpha-2 b, n(\%)$ & $41(43.6)$ & $30(41.7)$ & $11(50.0)$ & \\
\hline Conventional IFN, n (\%) & $28(29.8)$ & $22(30.6)$ & $6(27.3)$ & \\
\hline Completion, n (\%) & $71(75.5)$ & 60 (83.3) & $11(50.0)$ & 0.001 \\
\hline \multicolumn{5}{|l|}{ Responses } \\
\hline RVR (n=46), n (\%) & $28(60.9)$ & 24 (64.9) & $4(44.4)$ & 0.284 \\
\hline EVR $(n=86), n(\%)$ & 79 (91.9) & 65 (98.5) & $14(70.0)$ & $<0.001$ \\
\hline ETR $(n=89), n(\%)$ & 76 (85.4) & 63 (92.6) & $13(61.9)$ & 0.002 \\
\hline
\end{tabular}

All results for continuous variables are shown as mean \pm SD.

BMI, body mass index; ALT, alanine aminotransferase; HCV, hepatitis C virus; RNA, ribonucleic acid; APRI, aspartate aminotransferase-platelet ratio index; PegIFN, pegylated interferon; IFN, interferon; RVR, rapid virologic response; EVR, early virologic response; ETR, end of treatment response. 
EOT.

\section{Statistical analysis}

Student's t-tests and Mann-Whitney U-tests for continuous variables, $\chi^{2}$ and Fisher's exact tests for categorical variables were used for univariate analysis in the search for predictors of SVR. Variables with p-values of $<0.1$ by univariate analysis were included in a multiple binary logistic regression model. The changes of serum TC level and APRI scores from pretreatment to week 4 of treatment, EOT, and 24 weeks after EOT were analyzed by repeated measures analysis of variance (ANOVA). To determine independent effects of clinical variables associated with serum TC after antiviral therapy, univariable and multivariable generalized estimating equation (GEE) analyses were used with adjustment of time dependent changes of serum TC levels. All statistical evaluations were performed using SPSS version 17.0 (SPSS Inc., Chicago, IL, USA). p-values of $<0.05$ were considered statistically significant.

\section{RESULTS}

\section{Clinical characteristics of patients}

The mean age of the 94 eligible patients was 53 years, and $55 \%$ were males. The major viral genotypes were $1(41 \%)$ and 2 (52\%). Only $1(1.1 \%)$ patient had genotype 3, and $2(2.1 \%)$ had genotype 6. Among 60 liver biopsy specimens, 25\% revealed fibrosis grade 3 or 4 using the METAVIR scoring system, and
APRI scores showed significant correlation with grades of fibrosis $(\gamma=0.549, p<0.001)$. Therefore, APRI score was confirmed as a significant indicator of fibrosis in our study.

Twenty-three $(24.5 \%)$ patients were withdrawn from antiviral therapy due to side effects $(n=20)$ and lack of EVR $(n=3)$. Of 94 patients, $72(76.6 \%)$ had SVR: 26 of $38(68.4 \%)$ in genotype 1, 46 of $56(82.1 \%)$ in genotype non-1. Comparison of clinical characteristics between the SVR group and the non-SVR group is shown in Table 1. Pretreatment TC levels in the SVR group were not different from those in the non-SVR group ( $p=0.290$, Table 1), while being male, having a pretreatment HCV RNA titer $<5.5 \log \mathrm{IU} / \mathrm{mL}$, and completion of antiviral therapy were significant independent factors for predicting SVR in our patients by logistic regression analysis (male, odds ratio [OR] 47.2, 95\% confidence interval $[\mathrm{CI}] 2.38$ to $936.76, \mathrm{p}=0.012$; pretreatment HCV RNA <5.5 log IU/mL, OR 20.3, 95\% CI 1.21 to 341.8, $\mathrm{p}=0.037$; completion of antiviral therapy, OR 34.2, 95\% CI 1.91 to $611.7, \mathrm{p}=0.016$; data not shown).

\section{Changes of serum TC levels in the SVR and the non-SVR groups}

TC levels were significantly changed during and after antiviral therapy (Fig. 1). Serum TC levels decreased at week 4 of treatment and remained at the decreased levels until EOT in both SVR and non-SVR groups. At 24 weeks after EOT, the SVR group revealed significantly increased TC levels $(183 \pm 4.7 \mathrm{mg} / \mathrm{dL})$ compared to pretreatment TC levels $(167 \pm 3.6 \mathrm{mg} / \mathrm{dL})$, while such

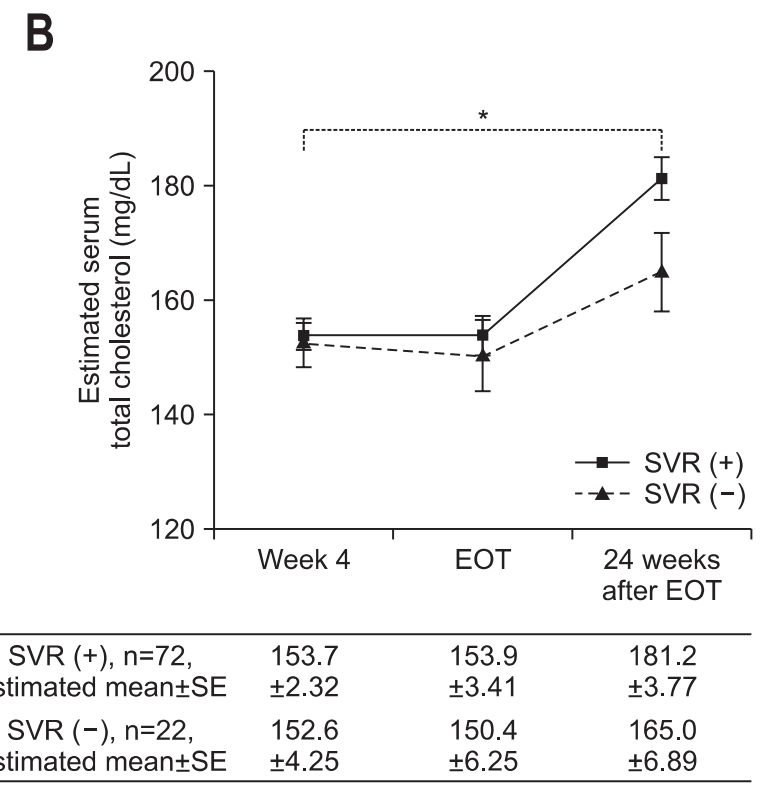

A

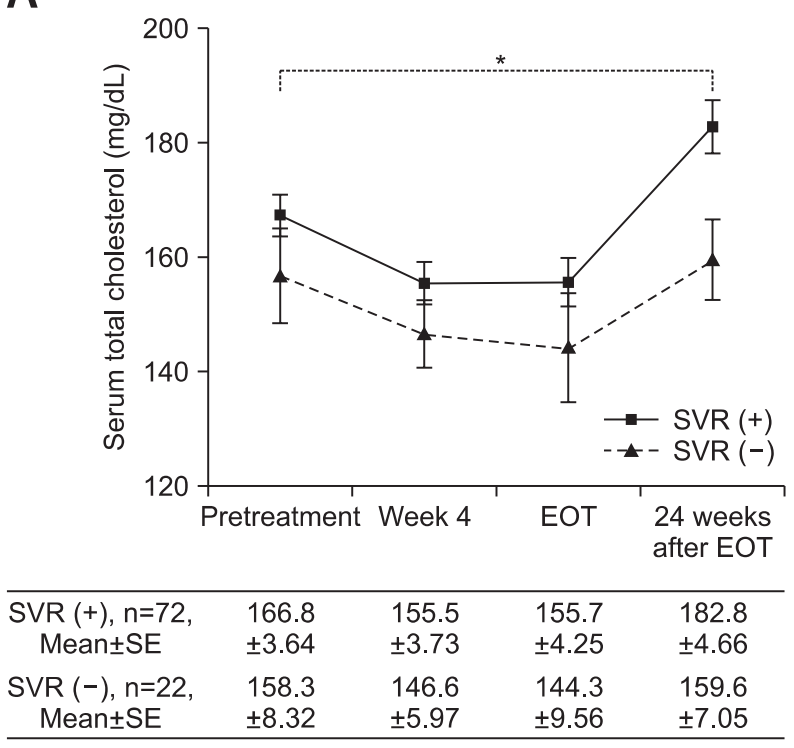

Fig. 1. (A) Changes in serum total cholesterol (TC) levels during and after antiviral therapy in chronic hepatitis C patients. Sustained virologic responders (SVR group, $\mathbf{\square}$ ) show a significant increase in the serum TC level 24 weeks after the end-of-treatment (EOT) compared to pretreatment serum TC. In contrast, there is no increase in the serum TC level 24 weeks after the EOT in the non-SVR group ( $\mathbf{\Delta})$. The changing patterns of serum TC levels during and after antiviral therapy are not significantly different between the SVR and non-SVR groups ( $\left.{ }^{*} \mathrm{p}=0.131\right)$ by repeated measure ANOVA. (B) Estimated change of in the serum TC levels during and after antiviral therapy in chronic hepatitis C patients after adjusting for the pretreatment cholesterol levels. Because the mean pretreatment cholesterol level of SVR group ( $\boldsymbol{\square})$ is higher than that of non-SVR group $(\boldsymbol{\Delta})$, a repeated measure ANOVA is performed after adjusting for the pretreatment cholesterol level. As a result, the change in the estimated serum TC levels after antiviral therapy is significantly different between the SVR and non-SVR groups ( $\mathrm{p}=0.044)$. 
an increase was not observed in the non-SVR group (Fig. 1A). The changes of TC levels during and after antiviral therapy were not significantly different between SVR and non-SVR group by repeated measure ANOVA analysis $(\mathrm{p}=0.131)$. However, TC level of SVR group was higher than non-SVR group although it was not significant (Table 1). Thus, we performed another repeated measure ANOVA after adjusting for pretreatment TC level to determine whether the change of TC levels from pretreatment to 24 weeks after EOT in SVR was different from that of nonSVR group. As a result, estimated serum TC levels after antiviral therapy significantly increased in SVR group compared to non-

Table 2. Clinical Variables Associated with the Pretreatment Serum Total Cholesterol Level in Chronic Hepatitis C Patients

\begin{tabular}{lcll}
\hline \multicolumn{1}{c}{ Variable } & $\begin{array}{c}\text { Regresssion } \\
\text { coefficient }(\beta)\end{array}$ & \multicolumn{1}{c}{$95 \% \mathrm{CI}$} & p-value \\
\hline Age, yr & -0.46 & -1.00 to 0.08 & 0.096 \\
Female & -0.64 & -13.36 to 12.09 & 0.921 \\
BMI, kg $/ \mathrm{m}^{2}$ & -2.11 & -4.50 to 0.29 & 0.084 \\
HCV RNA titer, log IU $/ \mathrm{mL}$ & 8.20 & -2.14 to 18.54 & 0.119 \\
Genotype 1 & -1.64 & -14.42 to 11.15 & 0.800 \\
Platelet count, $\times 10^{3} / \mu \mathrm{L}$ & 0.11 & 0.04 to 0.19 & 0.004 \\
METAVIR grade & -10.11 & -17.80 to -2.41 & 0.011 \\
Child-Pugh score & -21.42 & -35.60 to -5.25 & 0.010 \\
APRI & -5.07 & -9.73 to -0.41 & 0.033 \\
\hline
\end{tabular}

CI, confidence interval; BMI, body mass index; HCV, hepatitis C virus; RNA, ribonucleic acid; APRI, aspartate aminotransferase-platelet ratio index.
SVR group after adjusting for pretreatment TC ( $\mathrm{p}=0.044$, Fig. 1B).

\section{Clinical variables associated with pretreatment TC levels in $\mathrm{CHC}$}

As shown in Table 2, pretreatment TC levels were not associated with the HCV genotype or viral load. However, pretreatment serum TC levels declined significantly as Child-Pugh score increased or as platelet count decreased (Child-Pugh score, $\beta=-21.42$, 95\% CI -35.6 to $-5.25, p=0.010$; platelet count, $\beta=0.11,95 \%$ CI 0.04 to $0.19, \mathrm{p}=0.004$; Table 2). In addition, METAVIR grade of fibrosis and APRI score were found to be significantly correlated with pretreatment serum TC levels in CHC patients (grade of fibrosis, $\beta=-10.11,95 \%$ CI -17.8 to $-2.41, p=0.011$; APRI, $\beta=-5.07,95 \%$ CI -9.73 to $-0.41, p=0.033$; Table 2). Therefore, pretreatment TC levels of CHC patients showed significant negative association with their severity of hepatic fibrosis.

\section{Clinical variables associated with the change of serum TC levels after antiviral therapy in CHC}

As mentioned above, serum TC levels at 24 weeks after antiviral therapy for CHC significantly increased in the SVR group (Fig. 1). To evaluate independent variables associated with serum TC levels after adjusting for the time-dependent changes, longitudinal analyses using GEE were performed. According to univariable analyses, serum TC level was significantly affected by fibrosis markers including platelet count $(\beta=0.15,95 \%$ CI 0.01 to $0.29, p=0.034$; Table 3 ), METAVIR grade $(\beta=-9.59,95 \% \mathrm{CI}$ -16.93 to $-2.25, p=0.010$; Table 3$)$, Child-Pugh score $(\beta=-24.18$,

Table 3. Clinical Variables Associated with the Serum Total Cholesterol Level after Antiviral Therapy Identified Using Generalized Estimating Equations with an Adjustment for Time-Dependent Changes in the Total Cholesterol Level

\begin{tabular}{|c|c|c|c|c|c|c|}
\hline \multirow{2}{*}{ Variable } & \multicolumn{3}{|c|}{ Univariable analysis } & \multicolumn{3}{|c|}{ Multivariable analysis* } \\
\hline & $\begin{array}{l}\text { Regresssion } \\
\text { coefficient }(\beta)\end{array}$ & $95 \% \mathrm{CI}$ & p-value & $\begin{array}{l}\text { Regresssion } \\
\text { coefficient }(\beta)\end{array}$ & $95 \% \mathrm{CI}$ & $\mathrm{p}$-value \\
\hline Age, yr & -0.23 & -0.74 to 0.29 & 0.390 & - & & \\
\hline Female & 1.80 & -11.11 to 14.70 & 0.785 & - & & \\
\hline BMI, $\mathrm{kg} / \mathrm{m}^{2}$ & -1.03 & -3.48 to 1.41 & 0.406 & - & & \\
\hline HCV RNA titer, $\log \mathrm{IU} / \mathrm{mL}$ & 5.78 & -5.54 to 17.10 & 0.317 & - & & \\
\hline Genotype 1 & -6.23 & -18.87 to 6.40 & 0.333 & - & & \\
\hline Platelet count, $\times 10^{3} / \mu \mathrm{L}$ & 0.15 & 0.01 to 0.29 & 0.034 & - & & \\
\hline METAVIR grade & -9.59 & -16.93 to -2.25 & 0.010 & - & & \\
\hline Child-Pugh score & -24.18 & -38.65 to -9.72 & 0.001 & - & & \\
\hline APRI & -7.81 & -13.85 to -1.78 & 0.011 & -8.04 & -14.43 to -1.66 & 0.014 \\
\hline SVR & 14.44 & -0.69 to 29.58 & 0.061 & 12.62 & -1.69 to 26.94 & 0.084 \\
\hline
\end{tabular}

These variables show significant correlation with serum cholesterol by univariable analyses. The significant variables in univariable analyses including platelet count, METAVIR grade and Child-Pugh score are excluded in the multivariable model because they can be representative as APRI. CI, confidence interval; BMI, body mass index; HCV, hepatitis C virus; RNA, ribonucleic acid; APRI, aspartate aminotransferase-platelet ratio index; SVR, sustained virologic response.

${ }^{*}$ Model was adjusted for APRI and SVR. 
95\% CI -38.65 to $-9.72, p=0.001$; Table 3$)$, and APRI ( $\beta=-7.81$, 95\% CI -13.85 to $-1.78, p=0.011$; Table 3). Moreover, APRI was an independent factor associated with serum TC levels by the multivariable GEE analysis $(\beta=-8.04,95 \%$ CI -14.43 to -1.66 , $\mathrm{p}=0.014$; Table 3). In this multivariable model, the eradication of viruses (SVR) was also included because it was associated with serum TC levels with p-value of less than 0.1.

The changes of APRI during and after antiviral therapy for CHC were different from SVR and non-SVR group ( $\mathrm{p}=0.05$, Fig. 2A). At 24 weeks after EOT, SVR group revealed significantly decreased APRI $(0.46 \pm 0.06)$ compared to the pretreatment APRI $(1.36 \pm 0.14)$. The changes of APRI were different more significantly between SVR and non-SVR groups after adjusting for pretreatment APRI ( $<<0.001$, Fig. 2B). Therefore, the APRI continuously decreased during and after antiviral therapy, while serum TC levels decreased during antiviral therapy and then increased after EOT in SVR group.

\section{DISCUSSION}

In the present study, serum TC level significantly increased at 24 weeks after EOT among those in SVR group after antiviral therapy for CHC, but not in non-SVR group. Pretreatment and post-treatment TC levels were both independently associated with grade of hepatic fibrosis, while achievement of SVR was marginally associated with post-treatment TC levels. These results suggest that the change of serum TC levels according to antiviral therapy may be caused by improvement of hepatic fibrosis secondary to viral eradication rather than by the elimination of direct effects of HCV to the cholesterol metabolism in infected hepatocytes.

Serum TC level represents total amount of endogeneously synthesized and exogeneously absorbed cholesterols, which are transported into blood by binding to lipoproteins including very low density lipoprotein (VLDL), low density lipoprotein (LDL), and apolipoproteins. Endogenous cholesterol is synthesized in hepatocytes via the mevalonate pathway. ${ }^{9,21}$ On the other hand, exogenous cholesterol is endocytosed as the form of cholesterylester of LDL in hepatocytes and hydrolyzed to free cholesterol and fatty acid. ${ }^{22}$ Because most of these metabolic processes of lipid occur in the liver, serum TC level is closely related to the severity of liver diseases. ${ }^{1,2}$

Meanwhile, HCV has been documented to be able to interrupt lipid metabolism directly. HCV binds to LDL receptors in the membrane of hepatocytes for entry into the cells, ${ }^{7}$ and HCV particles are released from hepatocytes via VLDL secretion pathway. ${ }^{7,9,23}$ Moreover, HCV requires geranylgeranyl-pyrophosphate (PP) in the mevalonate pathway for replication, which may result in hypocholesterolemia, because HCV-infected cells spend most of the mevalonate as a substrate for geranylgeranyl-PP, rather than synthesis of cholesterol. ${ }^{22,24}$ Besides inhibition of cholesterol synthesis, HCV could impede cholesterol secretion into blood via the VLDL secretion pathway. ${ }^{23,25}$ These findings suggest that HCV itself may play a role to induce hypocholesterolemia independent of hepatic fibrosis, however, it has not been confirmed in human.
A

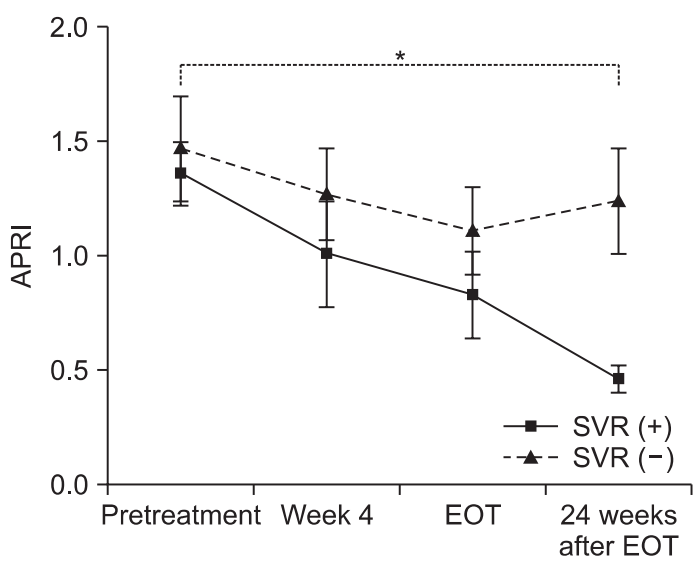

B

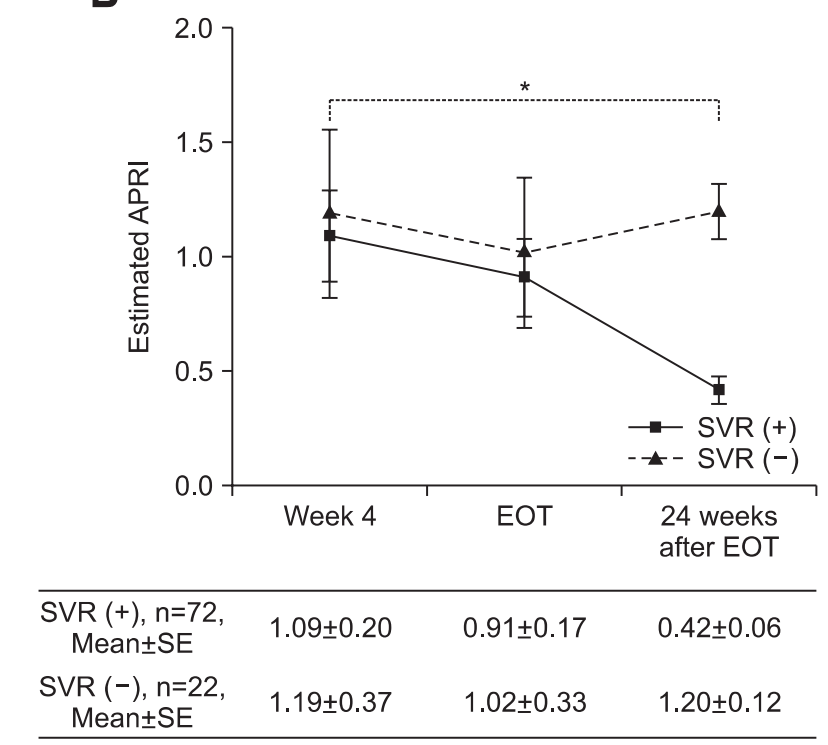

Fig. 2. (A) Change in the aspartate aminotransferase-platelet ratio index (APRI) during and after antiviral therapy for chronic hepatitis $\mathrm{C}$ patients. The APRI score improves in the sustained virologic response (SVR) group $(\boldsymbol{\square}, \mathrm{p}<0.001)$, but not in the non-SVR group $(\boldsymbol{\Delta}, \mathrm{p}=0.199)$. The changing APRI pattern during and after antiviral therapy is significantly different between the SVR and non-SVR groups ( ${ }^{*} \mathrm{p}=0.05$; repeated measure ANOVA). (B) Estimated change in the APRI level during and after antiviral therapy in chronic hepatitis C patients after adjusting for the pretreatment APRI. The change in the estimated APRI during and after antiviral therapy is significantly different between the SVR and non-SVR groups ( $\left.{ }^{*} p<0.001\right)$.

EOT, end-of-treatment. 
Many investigators have reported that reversals of hypocholesterolemia after antiviral therapy for $\mathrm{CHC}$ were observed among patient infected with HCV genotype 3, but there have been limited studies on the change of total cholesterol levels during and after antiviral therapy in genotype 1 and 2 infections. ${ }^{11,13,14,26}$ For the changing pattern of TC levels during antiviral therapy for genotype non-3 $\mathrm{CHC}$, some studies have shown gradual increase of TC levels, ${ }^{11,13}$ while other studies ${ }^{14,27}$ have shown decrease of TC levels which was compatible with our results. The present study clearly showed that SVR resulted in reversal of hypocholesterolemia in patient infected mostly with genotype non-3 (98.9\%).

On the other hands, the mechanism of reversal of hypocholesterolemia in HCV genotype non-3 infection can be different from that in genotype 3 infection. Thus, we hypothesized that the serum TC levels may increase after successful antiviral therapy by either eradication of HCV (SVR) or improvement of hepatic fibrosis which follows after viral eradication. To search the underlying reason for the increase of TC levels after SVR, we searched clinical variables associated with serum TC level, at pretreatment and post-treatment. Consequently, pretreatment TC level was inversely correlated with severity of liver fibrosis indicated as platelet count, METAVIR grade, Child-Pugh score and APRI. Although pretreatment TC level did not predict SVR in patients with genotype 1 or 2 infection, the elimination of hepatitis viruses from the liver was associated with the improvement of fibrosis grade and APRI. Those findings have not yet been sufficiently reported.

In addition, APRI scores decreased significantly in the SVR group than those in non-SVR group during and after antiviral therapy. As APRI is a simple and valid serum fibrosis marker, ${ }^{20,28}$ rapid reduction of APRI score may reflect a remarkably dynamic process related to improvement of liver fibrosis and inflammation during antiviral therapy. According to the multivariable analysis, APRI was the independent variable associated with the change of serum TC level after antiviral therapy. On the other hands, the viral eradication as indicated as SVR showed a marginal association with the change of TC levels. Therefore, the reversal of hypocholesterolemia in genotype 1 and 2 infected CHC after successful antiviral therapy may be mainly caused by improvement of hepatic fibrosis secondary to eradication of viruses rather than by direct effect of HCV eradication on cholesterol mechanism in CHC. However, further large prospective study is warranted to distinguish which factor plays the dominant role in increase of serum TC level after achieving SVR.

Among many other factors affecting serum cholesterol levels, such as race, age, gender, diabetes, and body mass index (BMI), ${ }^{29}$ BMI is one of the important determinants. ${ }^{30,31}$ Therefore, decreasing pattern of TC level during the antiviral therapy in our results is probably related to the decreased dietary intake and loss of body weight due to anorexia and other adverse effects of the therapy. However, age and BMI which were expected to affect serum TC levels significantly showed p-value less than 0.1 as the correlation analysis, probably due to small sample size.

The limitations of this study included retrospective design, relatively small sample size, and single center experience. The subgroup profiles of serum TC, which include LDL, VLDL, and high density lipoprotein, along with fasting glucose level were not available in the most of our subject patients due to retrospective design. We could not extensively investigate factors related to exogenous cholesterol uptake, such as dietary intake or body weight change during the course of antiviral therapy.

In conclusion, serum TC levels increased in the SVR group after antiviral therapy for CHC. The change may be explained by the improvement of liver fibrosis rather than by the eradication of HCV per se. Further investigation is needed to elucidate molecular mechanisms for the reversal of hypocholesterolemia in sustained viral responders, especially under the consideration of the change of hepatic fibrosis.

\section{CONFLICTS OF INTEREST}

No potential conflict of interest relevant to this article was reported.

\section{ACKNOWLEDGEMENTS}

This study was supported in part by grants from Korea Center for Disease Control and Prevention, research No. 2009-S3-R. The authors thank the assistances and supports on the statistical analysis provided by Medical Research Collaborating Center of Seoul National University Hospital and Professor Weechang Kang in Department of Information and Statistics, Daejeon University.

\section{REFERENCES}

1. Cicognani C, Malavolti M, Morselli-Labate AM, Zamboni L, Sama C, Barbara L. Serum lipid and lipoprotein patterns in patients with liver cirrhosis and chronic active hepatitis. Arch Intern Med 1997;157:792-796.

2. McIntyre N. Plasma lipids and lipoproteins in liver disease. Gut 1978;19:526-530.

3. Dai CY, Chuang WL, Ho CK, et al. Associations between hepatitis $\mathrm{C}$ viremia and low serum triglyceride and cholesterol levels: a community-based study. J Hepatol 2008;49:9-16.

4. Fabris C, Federico E, Soardo G, Falleti E, Pirisi M. Blood lipids of patients with chronic hepatitis: differences related to viral etiology. Clin Chim Acta 1997;261:159-165.

5. Moriya K, Shintani Y, Fujie H, et al. Serum lipid profile of patients with genotype $1 \mathrm{~b}$ hepatitis $\mathrm{C}$ viral infection in Japan. Hepatol Res 2003;25:371-376.

6. Serfaty L, Andreani T, Giral P, Carbonell N, Chazouillères 0, Poupon R. Hepatitis C virus induced hypobetalipoproteinemia: a 
possible mechanism for steatosis in chronic hepatitis C. J Hepatol 2001;34:428-434.

7. Monazahian M, Kippenberger S, Müller A, et al. Binding of human lipoproteins (low, very low, high density lipoproteins) to recombinant envelope proteins of hepatitis C virus. Med Microbiol Immunol 2000;188:177-184.

8. Siagris D, Christofidou M, Theocharis GJ, et al. Serum lipid pattern in chronic hepatitis C: histological and virological correlations. J Viral Hepat 2006;13:56-61.

9. Ye J. Reliance of host cholesterol metabolic pathways for the life cycle of hepatitis C virus. PLoS Pathog 2007;3:e108.

10. Petit JM, Benichou M, Duvillard L, et al. Hepatitis C virus-associated hypobetalipoproteinemia is correlated with plasma viral load, steatosis, and liver fibrosis. Am J Gastroenterol 2003;98:11501154.

11. Fernández-Rodríguez CM, López-Serrano $\mathrm{P}$, Alonso S, et al. Longterm reversal of hypocholesterolaemia in patients with chronic hepatitis $\mathrm{C}$ is related to sustained viral response and viral genotype. Aliment Pharmacol Ther 2006;24:507-512.

12. Gopal K, Johnson TC, Gopal S, et al. Correlation between betalipoprotein levels and outcome of hepatitis C treatment. Hepatology 2006;44:335-340.

13. Hamamoto S, Uchida Y, Wada T, et al. Changes in serum lipid concentrations in patients with chronic hepatitis $\mathrm{C}$ virus positive hepatitis responsive or non-responsive to interferon therapy. $\mathrm{J}$ Gastroenterol Hepatol 2005;20:204-208.

14. Tada S, Saito H, Ebinuma H, et al. Treatment of hepatitis C virus with peg-interferon and ribavirin combination therapy significantly affects lipid metabolism. Hepatol Res 2009;39:195-199.

15. Yu ML, Chuang WL. Treatment of chronic hepatitis C in Asia: when East meets West. J Gastroenterol Hepatol 2009;24:336-345.

16. The French METAVIR Cooperative Study Group. Intraobserver and interobserver variations in liver biopsy interpretation in patients with chronic hepatitis C. Hepatology 1994;20(1 Pt 1):15-20.

17. Borsoi Viana MS, Takei K, Collarile Yamaguti DC, Guz B, Strauss E. Use of AST platelet ratio index (APRI Score) as an alternative to liver biopsy for treatment indication in chronic hepatitis C. Ann Hepatol 2009;8:26-31.

18. Castéra L, Vergniol J, Foucher J, et al. Prospective comparison of transient elastography, Fibrotest, APRI, and liver biopsy for the assessment of fibrosis in chronic hepatitis C. Gastroenterology 2005;128:343-350.
19. Shaheen AA, Myers RP. Diagnostic accuracy of the aspartate aminotransferase-to-platelet ratio index for the prediction of hepatitis C-related fibrosis: a systematic review. Hepatology 2007;46:912921.

20. Wai CT, Greenson JK, Fontana RJ, et al. A simple noninvasive index can predict both significant fibrosis and cirrhosis in patients with chronic hepatitis C. Hepatology 2003;38:518-526.

21. Goldstein JL, Brown MS. Regulation of the mevalonate pathway. Nature 1990;343:425-430.

22. Goldstein JL, Brown MS, Anderson RG, Russell DW, Schneider WJ. Receptor-mediated endocytosis: concepts emerging from the LDL receptor system. Annu Rev Cell Biol 1985;1:1-39.

23. Agnello V, Abel G, Elfahal M, Knight GB, Zhang QX. Hepatitis C virus and other flaviviridae viruses enter cells via low density lipoprotein receptor. Proc Natl Acad Sci U S A 1999;96:12766-12771.

24. Kapadia SB, Chisari FV. Hepatitis C virus RNA replication is regulated by host geranylgeranylation and fatty acids. Proc Natl Acad Sci U S A 2005;102:2561-2566.

25. Molina S, Castet V, Fournier-Wirth C, et al. The low-density lipoprotein receptor plays a role in the infection of primary human hepatocytes by hepatitis C virus. J Hepatol 2007;46:411-419.

26. Minuk GY, Weinstein S, Kaita KD. Serum cholesterol and lowdensity lipoprotein cholesterol levels as predictors of response to interferon therapy for chronic hepatitis C. Ann Intern Med 2000;132:761-762.

27. Corey KE, Kane E, Munroe C, Barlow LL, Zheng H, Chung RT. Hepatitis $\mathrm{C}$ virus infection and its clearance alter circulating lipids: implications for long-term follow-up. Hepatology 2009;50:10301037.

28. Lackner C, Struber G, Liegl B, et al. Comparison and validation of simple noninvasive tests for prediction of fibrosis in chronic hepatitis C. Hepatology 2005;41:1376-1382.

29. Rodriguez C, Pablos-Méndez A, Palmas W, Lantigua R, Mayeux R, Berglund L. Comparison of modifiable determinants of lipids and lipoprotein levels among African-Americans, Hispanics, and NonHispanic Caucasians $>$ or $=65$ years of age living in New York City. Am J Cardiol 2002;89:178-183.

30. Ramalho F. Hepatitis $C$ virus infection and liver steatosis. Antiviral Res 2003;60:125-127.

31. Clouston AD, Jonsson JR, Purdie DM, et al. Steatosis and chronic hepatitis C: analysis of fibrosis and stellate cell activation. J Hepatol 2001;34:314-320. 